\title{
Examination of Preservice Teachers' Views on Peer Learning
}

\author{
Jale IPEK ${ }^{1}$ \\ ${ }^{1}$ Ege University, Faculty of Education, Izmir, Turkey \\ Correspondence: Jale IPEK, Ege University, Faculty of Education, Izmir, Turkey. E-mail: jale.ipek@ege.edu.tr
}

Received: April 5, $2021 \quad$ Accepted: May 8, $2021 \quad$ Online Published: May 14, 2021
$\begin{aligned} & \text { doi:10.5539/jel.v10n3p149 URL: https://doi.org/10.5539/jel.v10n3p149 }\end{aligned}$

\begin{abstract}
This study aimed to examine the preservice teachers' views on the process after entering Code.org and block-based programming (Scratch) training programs, which are carried out by the peer learning method. The study group of the research consists of 41 preservice teachers at the Computer Education and Instructional Technologies departments of a state university and took the Special Teaching Methods 2 course in the spring semester of the 2017-2018 academic year. Considering the criteria determined by the researcher, 7 preservice teachers were selected as educators. As students, 34 preservice teachers participated in the study. In this study, a qualitative research method was used to determine the opinions of preservice teachers on the Code.org and Scratch training programs, which are carried out by the peer learning method. As a data collection tool, the opinion form for the Code.org training programs, the structure of opinion determination on the Scratch training programs, and the personal information form were used. The total duration of the study consists of eight weeks. Data from the preservice teachers were collected weekly using data collection tools and a content analysis technique used in the analysis of the data. At the end of the study, the opinions of the preservice teachers on the study conducted with the peer learning method were determined. It can be said that preservice teacher generally has positive views on peer learning and are satisfied with the peer learning method.
\end{abstract}

Keywords: social learning, peer learning, block-based programming

\section{Introduction}

Constructivism, one of the most used pedagogical approaches, has a social learning process in principle. There are many methods used under this scope. One of them is peer learning. The concepts of constructivism and peer learning have been explained within this context.

\subsection{Constructivism}

Constructivism is a teaching and learning approach based on the assumption that learning (cognition) results from "mental structure". Learners learn by combining their previous knowledge with new information. Advocates of constructivism believe that learning is also influenced by the beliefs and attitudes of students as well as the context of teaching a thought. In psychology, constructivism is a learning theory that explains how people can acquire knowledge and learn. The theory suggests that people generate knowledge and meaning from their experiences. Piaget's Constructivist learning theory has a broad impact on learning theories and teaching methods in education and is an underlying theme in many educational reform movements (Bada \& Olusegun, 2015).

The constructivist perspective supports students to learn through interaction with others. Students work together as peers and apply their combined knowledge to the solution of the problem. The dialogue resulting from this combined effort offers students the opportunity to test and refine their understanding in a continuous process (Tam, 2000).

Chung (1991) listed the following four basic features of constructivist learning environments that should be considered when implementing constructivist teaching strategies; information will be shared between teachers and students, teachers and students will share authority, the role of the teacher is the facilitator or guide, and learning groups will consist of a small number of different students.

Constructivism suggests developing social and communication skills by creating a classroom environment that emphasizes collaboration and exchanging ideas. By sharing in group projects, students should learn to express their opinions clearly and collaborate effectively on tasks. Therefore, students must exchange ideas and learn to 
negotiate with others, and socially evaluate their contributions. This is important for real-world success, as they will always have a variety of experiences where they will have to collaborate with others and examine the opinions of others (Bada \& Olusegun, 2015). A good introduction answers these questions in just a few pages and, by summarizing the relevant arguments and the past evidence, gives the reader a firm sense of what was done and why (Beck \& Sales, 2001, pp. 100-102). The concept of peer learning has been analyzed below as it is significant to use the method of peer learning in which cooperation is critical and employed.

\subsection{Peer Learning}

Peer learning is defined as creating knowledge and skills through interaction between people who have similar characteristics or share a similar situation and in which no one acts as the professional teacher (Topping, 2005). The peer learning method involves asking students a question, giving them time to think, followed by discussing their answers with a peer, and finally explaining the results to the whole class (Zhu, 2007). The main goal of peer learning is to use student interaction during lessons and focus students' attention on basic concepts (Mazur, 1999). Discussions amongst peers enable them to get rid of monotonous learning, ultimately thinking for themselves and expressing their thoughts instead of simply absorbing the materials (Mazur, 1999). Topping argues that if peer learning is used in a planned way, it will support learning (Topping, 2005). The peer training method supports the development of knowledge and skill of both the teacher and student, which is why it should be encouraged to benefit from peer education (Rees, Quinn, Davies, \& Fotheringham, 2016). In their study, Bene and Bergus (2014) stated that similar studies have shown that peer education positively affects teachers and students. Brannagan et al. (2013) however, argued that students who study with their peers may be more anxious than the lesson taught with the teacher. The reason for this anxiety potentially being due to the insufficient training of the educators. ChanLin (2012) states in his study that the interaction and collaborative process between peers contributes to the achievement of the academic goals of learning. Michinov, Brunot, Le Bohec, Juhel and Delaval (2011) stated in their study that the interaction of students with their peers is also a practical way of learning in an online environment. Puzziferro (2008) says that peer interaction has become a fundamental and widely accepted method for encouraging social participation in distance education environments. Knobe et al. (2010) pointed out that those who benefit most from the peer learning method are the teaching students who take part in peer education. It can be said that peer learning can make a very positive contribution among teaching students.

It is crucial to carry out activities and sample studies to improve the knowledge and skill of teachers and students about peer education (AbdulRaheem, Yusuf, \& Odutayo, 2017). There are many advantages of peer learning (Mazur, 1997) however, more research is needed to make full use of the opportunities that the peer learning method can provide preservice teachers (Stenberg \& Carlson, 2015). Exploring the use of this method and the options and effects it carries further will contribute to this topic's place within the literature.

\subsection{Purpose of the Research}

This study aims to examine preservice teachers' views on the process after entering Code.org and block-based programming training programs, which are carried out by the peer learning method. For this purpose, we looked for an answer to the following questions.

1) What are the satisfaction levels of the preservice teachers regarding the training programs carried out with the peer learning method?

2) What are the opinions of the preservice teachers about the training programs carried out with the peer learning method?

\section{Method}

In this study, a qualitative research method was used to determine the opinions of preservice teachers on Code.org and block-based programming training programs carried out with the peer learning method.

\subsection{Working Group}

The study group of this research consists of preservice teachers of the Department of Computer Education and Instructional Technology studying at a state university at a higher education level. They have also undertaken the 'Special Teaching Methods ' 2 ' course in the spring semester of the 2017-2018 academic year. Among the preservice teachers, 41 people, $24(\%)$ male, and $17(\%)$ female, seven preservice teachers were chosen as educators by the researcher. The other 34 preservice teachers participated in the study as students.

\subsection{Educator Selection in Peer Learning}

The researcher selected preservice teachers who had experience in block-based coding and Code.org to select 
preservice teachers for the teaching position in peer learning. These preservice teachers are educated on this subject having attended various related seminars and courses at institutions and organizations and are also experienced in working with these matters.

\subsection{Data Collection Tools}

This research aims to determine the opinions of the preservice teachers on the platform of teaching programming (Code.org), and processes of teaching block-based programming carried out with the peer learning method. For this purpose, an opinion form developed by the researcher and a personal information form were utilized.

\subsection{Research Design}

First, as indicated in Figure 1, the selection of students chosen as educators was carried out during the research process. The Code.org training was held for three weeks after the educator selections were made. After this process, data collection was carried out on the Code.org training program, with a personal information form and an opinion form. After collecting the data, the block-based programming training (Scratch) was carried out for three weeks. Preservice teachers were then asked to develop projects over two weeks that complied with the criteria by using the block-based programming (Scratch) environment. After the training, data were collected on the block-based programming training program with personal information and an opinion form.

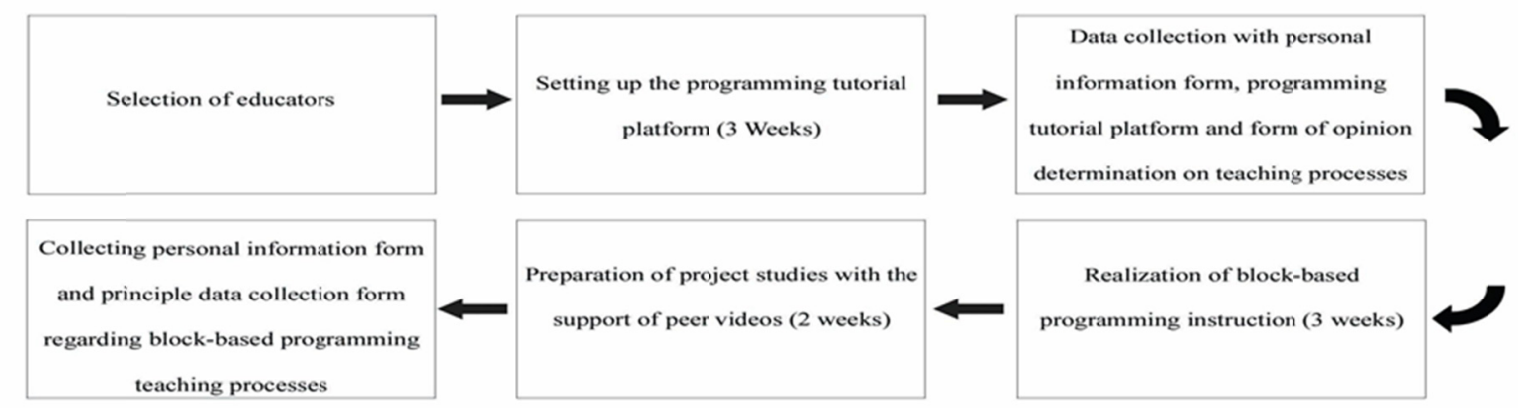

Figure 1. Research design

\subsection{Teaching Content}

As indicated in Table 1, this study lasted 8-weeks. The study included teaching with Code.org for the first three weeks by peers, followed by block-based programming for three weeks. In the last two weeks of the study, preservice teachers prepared projects with the support of supportive education videos that the educators had created had created. Peers took part in the process collaboratively and interactively by discussing with each other and seeking new solutions. Details on the training programs are given below.

Table 1. Teaching content

\begin{tabular}{ll}
\hline Week & Content \\
\hline Week 1 & $\begin{array}{l}\text { Completing the Code.org 1-13 section } \\
\text { Week } 2\end{array}$ \\
Completing the Code.org 13-18 section \\
Week 3 & $\begin{array}{l}\text { Completing the Code.org 18-24 section } \\
\text { Data collection on the Code.org training programs with the personal information form and opinion form }\end{array}$ \\
Week 4 & Making a game similar to the "Obstacle avoiding cat game" with block-based programming \\
Week 5 & Making a game similar to the "Cat-Knocker game" with block-based programming \\
Week 6 & Making a game similar to the "Ping Pong game" with block-based programming \\
Week 7 & Preservice teachers prepare their projects \\
Week 8 & Data collection on the block-based programming training program with personal information form and opinion form \\
\hline
\end{tabular}

\subsubsection{Code.org Training}

From the teacher's account on the Code.org platform, a classroom was created in order to follow the progress, work, and process of the preservice teachers. The preservice teachers entered the created classroom with the code given by the educators. In the first week of the three-week Code.org training, the educators introduced the 
platform and its structures to the preservice teachers. Following this, the preservice teachers were asked to complete 1-13 parts in the first week, 13-18 parts in the second week, and 18-24 parts in the third week of the training program consisting of 24 parts. As seen in Figure 2, the progress of preservice teachers was followed and recorded weekly. Throughout the course, in problem situations, the educators provided support to the preservice teachers in the classroom. Programming tasks that the preservice teachers could not complete have been solved with an interactive classroom demonstration by the educators. In addition to this situation, they also supported preservice teachers with any individual questions. Each week, after completion of the training, preservice teachers were asked to fill in the data collection tools in the classroom.

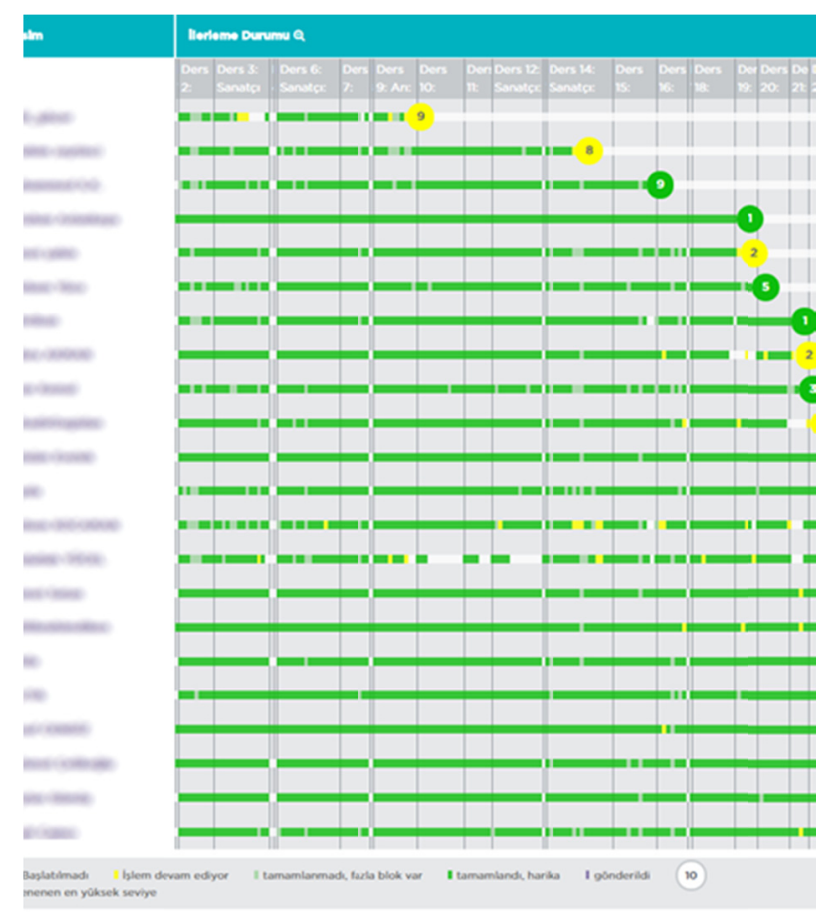

Figure 2. An example of preservice teachers' progress chart on the Code.org platform

\subsubsection{Block-Based Programming (Scratch) Training}

Block-based programming (Scratch) training is planned as three weeks in total. As a result of the scheduled training, the principles were determined from part to whole (from easy to difficult). The preservice teachers were asked to produce a product with block-based programming and to prepare educational video material about the production of their products.

In the first week of the three-week block-based programming training, the educators explained the interface and the use and operation of the blocks in the block-based programming environment to the preservice teachers. After showing simple examples of the functioning of the blocks, the preservice teachers were asked to do a similar study to the "cat game running away from the obstacles" that had been previously shown to them. The preservice teachers completed their studies as shown in Figure 3 by making various alterations similar to the programming structure. The preservice teachers have sent this work conducted during the lesson to the educators after the lesson. Then, opinions of the preservice teachers regarding the process have been collected with the data collection tool. 


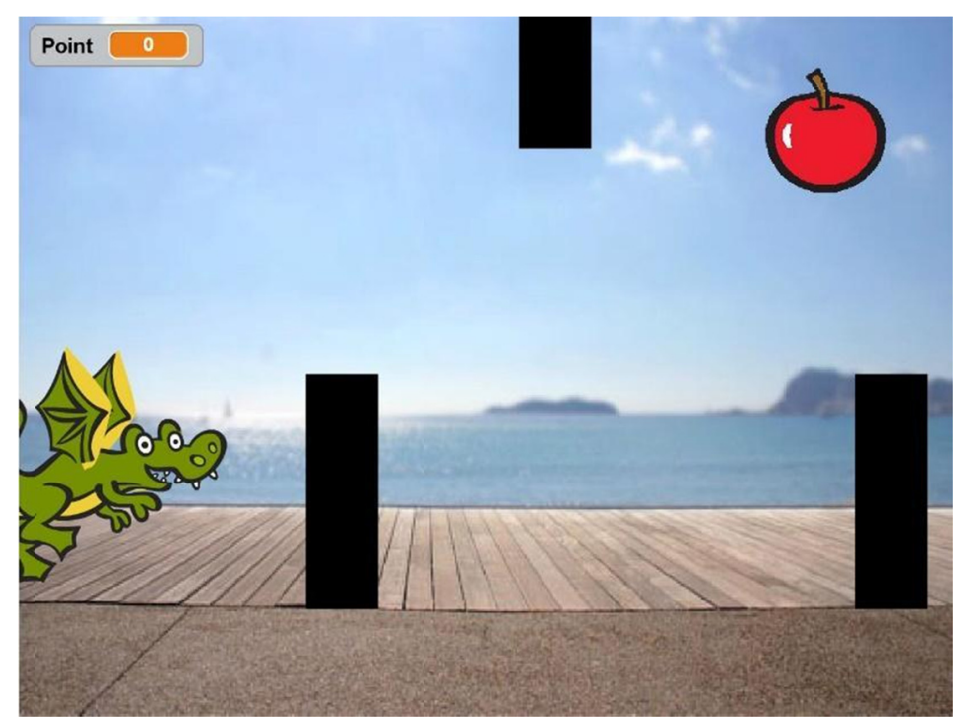

Figure 3. An example of student work in first week of the block-based programming training

In the second week of the three-week program, the educators answered any questions about the work they were asked to do the previous week. The preservice teachers were given the task to create their projects to be completed in accordance with the programming structure of the "Kedi-Tokmak Game" study, which is presented as an example in the lesson. The preservice teachers assembled the projects by adding various components, examples included in Figure 4. These were sent to the teachers at the end of the lesson on the weekly evaluation form. Then thoughts of the preservice teachers were taken with the help of the data collection tool.

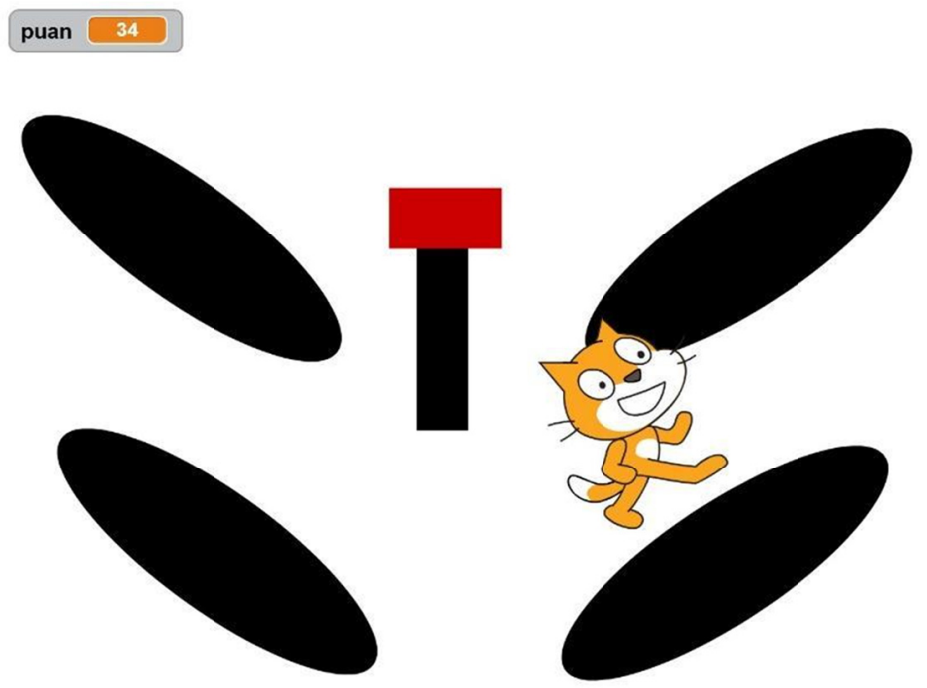

Figure 4. Block-based programming training, an example from the work of preservice teachers in the second week

In the third week of block-based programming training, preservice teachers were asked to do a "Ping Pong game" that contained a specific purpose and characteristics. After the preservice teachers completed the task during the lesson period, as shown in Figure 5, they sent the results to the educators on the weekly evaluation form. Educators provided guidance and information tailored to each preservice "teacher's project". After completing the course project, feedback of the preservice teachers about this week was obtained using data collection tools. 

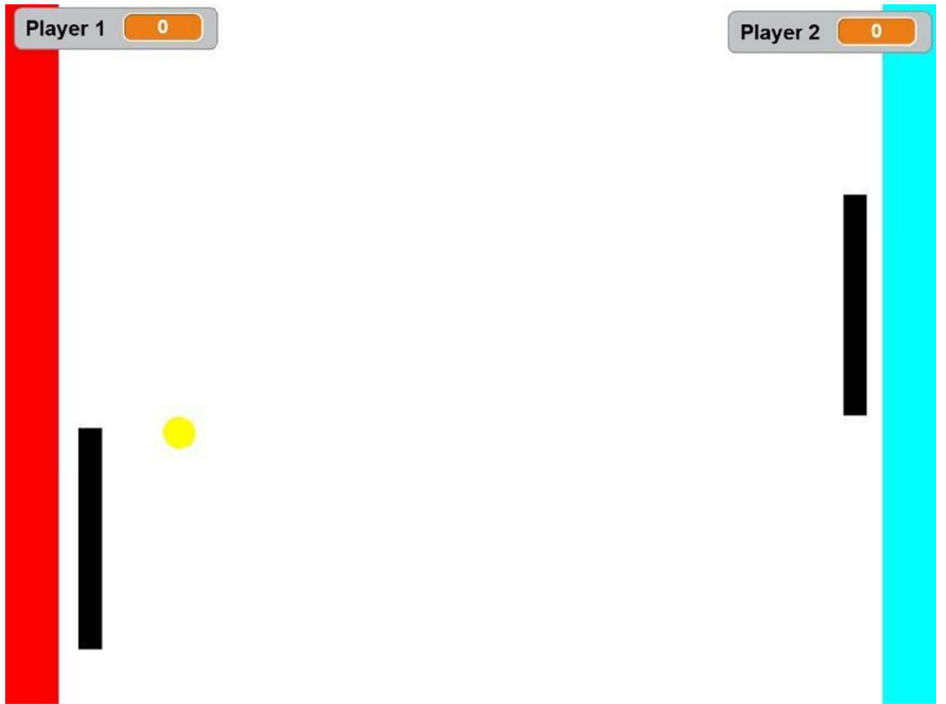

Figure 5. An example from the preservice teacher studies in the third week of block-based programming training

\subsection{Preparation of Preservice Teachers Projects}

The preservice teachers tried to create unique and creative programming products in their projects. The preservice teachers first identified an aim to start their studies. After preparing the scenario suitable for their chosen aim, they started to create their work. After completing their work, they designed an instructive video material on how their work was accomplished. All their files included, they have sent their work to the educators.

\subsection{Data Analysis}

Content analysis technique was used in the analysis of the data. During the analysis process, the data was organized and analyzed in detail by the researcher. The data obtained from the study was coded according to the researchers' investigations. Regarding the differences seen in the codes, a standard code was determined by the researcher. In addition, the frequencies found in the present data show the number of codes.

\subsection{The Role of the Researcher}

During the research process, the researcher was in the position of a participant observer. The researcher served as a guide by staying with the working group throughout the research.

\section{Results}

Below are presented findings regarding the purpose of the research and research questions. Also shown are direct quotations retrieved from the opinions of the preservice teachers.

3.1 RQ1: Findings on the Research Question "What Are the Satisfaction Levels of the Preservice Teachers Regarding the Two Training Programs Carried out with the Peer Learning Method?" Are Presented Below

Findings regarding the research question are given in Table 2. As seen in Table 2, the average satisfaction level of the participants with the platform of teaching programming is determined as 3,89 when evaluated from 1 to 5 .

The average satisfaction level of the Code.org training period was 3.89. The average level of satisfaction of the block-based programming training period was found to be 4.37 .

Table 2. Preservice teachers' satisfaction levels with the peer learning method

\begin{tabular}{ll}
\hline Training section & Satisfaction level average \\
\hline Code.org training & 3.89 \\
Block-based programming training & 4.37 \\
\hline
\end{tabular}

3.2 RQ2: Findings on the Research Question "What Are the Opinions of the Preservice Teachers on the Two Training Programs Carried out with the Peer Learning Method?" Are Presented Below

During the data collection process conducted on the research question, data was collected on the training 
program period and the overall peer learning method. The obtained data is explained below.

As indicated in Table 3, in the weekly distribution of preservice teachers' opinions regarding the platform of teaching programming, for week 1 , it is seen that of the participants, $35.29 \%$ have found it good, 11.76 beneficial, 11.76 enjoyable, $8.82 \%$ intense, $8.82 \%$ didactic, 5.88\% successful, 5.88\% long, $5.88 \%$ difficult, $2.94 \%$ sufficient, and $2.94 \%$ boring. For week 2 , of the participants, $21.88 \%$ have found it good, $31.25 \%$ beneficial, $21.88 \%$ enjoyable, $18.75 \%$ difficult, and $6.25 \%$ boring. For week 3 , of the participants, $35 \%$ have found it good, $25 \%$ beneficial, $15 \%$ enjoyable, $10 \%$ difficult, $10 \%$ boring, and $5 \%$ fluent.

Table 3. Distribution of preservice teachers' views on the Code.org training program

\begin{tabular}{llll}
\hline Opinion & Week 1 (\%) & Week 2 (\%) & Week 3 (\%) \\
\hline Good & 35.29 & 21.88 & 35 \\
Usefull & 11.76 & 31.25 & 25 \\
Fun & 11.76 & 21.88 & 15 \\
Intense & 8.82 & 0 & 0 \\
Informative & 8.82 & 0 & 0 \\
Successful & 5.88 & 0 & 0 \\
Long & 5.88 & 0 & 0 \\
Hard & 5.88 & 18.75 & 10 \\
Enough & 2.94 & 0 & 0 \\
Boring & 2.94 & 6.25 & 10 \\
Consistent & 0 & 0 & 5 \\
\hline
\end{tabular}

As indicated in Table 4, in the weekly distribution of preservice teachers' opinions regarding the process of teaching block-based programming, for week 4 , it is seen that of the participants, $26.32 \%$ have found it enjoyable, $26.32 \%$ good, $15.79 \%$ beneficial, $17.79 \%$ informative, $5.26 \%$ successful, $5.26 \%$ didactic, and $5.26 \%$ easy. In week $5,20 \%$ of the preservice teachers found it fun, $20 \%$ good, $16.67 \%$ useful, $30 \%$ informative, $3.33 \%$ successful, $3.33 \%$ impressive, $3.33 \%$ slow and $3.33 \%$ of them found it to be creative. Looking at week 6 , it is seen that $30.43 \%$ of the preservice teachers found it enjoyable, $34.78 \%$ good, $26.09 \%$ useful, $4.35 \%$ challenging and $4.35 \%$ insufficient.

Table 4. Distribution of preservice teachers' views on the block-based programming (Scratch) training program

\begin{tabular}{llll}
\hline Opinion & Week 4 (\%) & Week 5 (\%) & Week 6 (\%) \\
\hline Fun & 26.32 & 20 & 30.43 \\
Good & 26.32 & 20 & 34.78 \\
Useful & 15.79 & 16.67 & 26.09 \\
Informative & 15.79 & 0 & 0 \\
Successful & 5.26 & 0 & 0 \\
Educational & 5.26 & 0 & 0 \\
Easy & 5.26 & 0 & 0 \\
Informative & 0 & 30 & 0 \\
Successful & 0 & 3.33 & 0 \\
Impressive & 0 & 3.33 & 0 \\
Slow & 0 & 3.33 & 0 \\
Creative & 0 & 3.33 & 0 \\
Compelling (Hard) & 0 & 0 & 4.35 \\
Insufficient & 0 & 0 & 4.35 \\
\hline
\end{tabular}

As indicated in Table 5, 87.50\% of the preservice teachers have positive and $12.50 \%$ negative views regarding the peer learning process. The statements of some of the preservice teachers who share these views have been stated. One of the preservice teachers said (P7) "There is nothing negative, I find peer learning to be useful in terms of asking questions to our friends more easily." In his statement he reported that asking questions to his peers is easier thanks to the peer learning process. Another preservice teacher (P21) stated that peer learning facilitates a straightforward learning process with the statement "it provides easy learning". One of the teachers said (P3) "It is easier and more efficient to get help from our friends when we get stuck." He states that 
getting help from his peers is easy and efficient. Another preservice teacher (P11) states that there is a feeling of enjoyable solidarity: "We have done it together with great fun and helped each other". One of the preservice teachers (P37): "I am very pleased with the lessons we have undertaken with our friends." Another preservice teacher (P27) stated that "It is very useful for learning together", another preservice teacher (P15) said "In my opinion, peer learning is quite useful and makes the lessons more understandable". With his expression, he that peer learning is useful as it makes the lessons more understandable. On the other hand, one of the participants (P35) stated that peer learning is not beneficial by saying, "It is not very useful." Another participant (P25) expressed that the content of the teaching program did not start from a sufficient level for himself/herself by saying, "They started from simple examples, and it was easy and boring as we had already known them."

Table 5. Distribution of preservice teachers' positive and negative opinions about the peer learning method

\begin{tabular}{ll}
\hline Opinion & Participants (\%) \\
\hline Positive & 87.5 \\
Negative & 12.5 \\
\hline
\end{tabular}

\section{Conclusion and Discussion}

\subsection{RQ1: Findings on the Research Question "What Are the Satisfaction Levels of the Preservice Teachers} Regarding the Training Programs Carried out with the Peer Learning Method?" Are Presented Below

The average satisfaction level of the participants with the platform of teaching programming is determined as 3.89 when evaluated from 1 to 5 . Within this context, it is seen that participants were highly satisfied with the process of teaching programming. Likewise, the average satisfaction level is determined as 4.37 out of 5 when the data on teaching block-based programming is evaluated. In this regard, it is seen that participants were highly satisfied with the process of teaching block-based programming carried out with the peer learning method.

\subsection{RQ2: Findings on the Research Question "What Are the Opinions of the Preservice Teachers on the Training Programs Carried out with the Peer Learning Method?" Are Presented Below}

When the opinions of preservice teachers regarding the Code.org training programs are examined, it is seen that they are gathered around the perception of good, useful, fun, intense, instructive, successful, long, difficult, sufficient, boring and consistent. When the distribution of these perceptions is examined, it is seen that they reinforce the perception that the Code.org training program can be considered positive for learning.

It is seen that the opinions grouped as good, useful and entertaining each week are more significant than the other more negative perceptions. Concluding from this data, it can be said that preservice teachers see the peer learning method used in the Code.org training program to be a more enjoyable, beneficial and pleasant learning method.

When the opinions of preservice teachers regarding the block-based (Scratch) training program are examined, it is seen that the impressions "fun", "good", "useful", "informative", "successful", "educational", "easy", "instructive", "successful", "impressive", "slow", "creative", "challenging" and "inadequate" are present. Looking at the distributions, negative impressions are mentioned very little for this program. In general, it is detected that most of the preservice teachers share positive thoughts. It is seen that the impressions "fun", "good" and "useful" are more prominent than other impressions every week.

It can be concluded that preservice teachers find the peer learning method used in the block-based programming training program to be good and useful for their learning.

The collected data on the opinions of the preservice teachers on the peer learning method (87.5\%) show that the majority had a positive opinion on the use of this method.

When we look at the positive thoughts on the peer learning method, it is seen that preservice teachers can communicate with their peers more easily and without hesitation. This way, they can communicate their problems comfortably and solve them by discussing them together, enjoying a fun process with their peers, and learning becomes more efficient. Opposing this point of view, a small percentage of preservice teachers (12.5\%) are bored with this program and do not find it useful.

Studies are showing that the use of peer learning methods has a positive effect on students (Bene \& Bergus, 2014). Consequently, our own results are aligned with those found in Bene \& Bergus's study. During the block-based training program it is found that preservice teachers use expressions such as "insufficient", "boring", "slow" and "hard" Brannagan et al. (2013) stated that in their study, students were more anxious and stressed 
during the peer learning method. It was stated that the reason for this situation might be due to the insufficient level of educators. Contrary, preservice teachers in our study did not think that the educators were at an insufficient level, only $12.5 \%$ mentioning the words "insufficient", "boring", "slow" and "challenging". Brannagan et al. (2013), however, show that if educators are selected carefully, with the criteria determined by the study's researcher, they are found to be at a sufficient level. It was found that $87.5 \%$ of the preservice teachers who participated in the study had a positive opinion about the process. This finding can be in connection with the fact that peer learning stated in the literature supports improving students' knowledge and skills (Rees, Quinn, Davies, \& Fotheringham, 2016) and increases peer interaction which is significant for academic success (Bohec, Juhel, \& Delaval, 2011; ChanLin, 2012). The Preservice teachers who interacted with their peers in the peer learning method expressed that this method has been beneficial to them. This study was conducted in order to determine the opinions of preservice teachers about the peer learning method. As a result of the study, it was found that preservice teachers generally had positive views on peer learning. In conclusion, the use of the peer learning method on preservice teachers should be supported, and peer learning should be encouraged.

\subsection{Suggestions}

Peer learning is a method that can be viewed positively by preservice teachers. It is a teaching method that every student can complete without getting bored and collaboration is carried out effortlessly. Therefore, an efficient peer to peer interaction is ensured, ultimately affecting students in a positive way. Research on peer learning provides guidance for practitioners that want to use this method.

In this sense, studies that deal with different variables related to the peer learning method should be carried out to guide both practitioners and those working within this field. If collaborative work is considered, the peer learning method can be seen as an effective method of carrying this out. It is important to carry out similar studies in other disciplines of education.

\section{References}

AbdulRaheem, Y., Yusuf, H. T., \& Odutayo, A. O. (2017). Effect of Peer Tutoring on Students' Academic Performance in Economics in Ilorin South, Nigeria. Journal of Peer Learning, 10(1), 95-102.

Bada, S. O., \& Olusegun, S. (2015). Constructivism learning theory: A paradigm for teaching and learning. Journal of Research \& Method in Education, 5(6), 66-70.

Bene, K. L., \& Bergus, G. (2014). When learners become teachers. Family Medicine, 46, 783-787.

Brannagan, K. B., Dellinger, A., Thomas, J., Mitchell, D., Lewis-Trabeaux, S., \& Dupre, S. (2013). Impact of peer learning on nursing students: Perceptions of learning environment, self-efficacy, and knowledge. Nurse Education Today, 33(11), 1440-1447. https://doi.org/10.1016/j.nedt.2012.11.018

Broadbent, J., \& Poon, W. L. (2015). Self-regulated learning strategies \& academic achievement in online higher education learning environments: A systematic review. The Internet and Higher Education, 27, 1-13.

ChanLin, L. J. (2012). Learning strategies in web-supported collaborative projects. Innovations in Education and Teaching International, 49(3), 319-331. https://doi.org/10.1080/14703297.2012.703016

Chung, J. (1991). Collaborative learning strategies: The design of instructional environments for the emerging new school. Educational Technology, 31(12), 15-22.

Johnson, R. D., Gueutal, H., \& Falbe, C. M. (2009). Technology, trainees, metacognitive activity and e learning effectiveness. Journal of Managerial Psychology, 24(6). https://doi.org/10.1108/02683940910974125

Knobe, M., Münker, R., Sellei, R. M., Holschen, M., Mooij, S. C., Schmidt-Rohlfing, B., \& Pape, H. C. (2010). Peer learning: A randomised controlled trial using student-teachers to teach musculoskeletal ultrasound. Medical Education, 44(2), 148-155.

Mazur, E. (1999). Peer instruction: A user's manual.

Michinov, N., Brunot, S., Le Bohec, O., Juhel, J., \& Delaval, M. (2011). Procrastination, participation, and performance in online learning environments. Computers \& Education, 56(1), 243-252. https://doi.org/10.1119/1.19265

Puzziferro, M. (2008). Online technologies self-efficacy and self-regulated learning as predictors of final grade and satisfaction in college-level online courses. The Amer. Jrnl. of Distance Education, 22(2), 72-89. https://doi.org/10.1080/08923640802039024

Rees, E. L., Quinn, P. J., Davies, B., \& Fotheringham, V. (2016). How does peer learning compare to faculty 
teaching? A systematic review and meta-analysis. Medical Teacher, 38(8), 829-837. https://doi.org/10.3109/0142159X.2015.1112888

Stenberg, M., \& Carlson, E. (2015). Swedish student nurses' perception of peer learning as an educational model during clinical practice in a hospital setting-An evaluation study. BMC Nursing, 14(1), 1-7. https://doi.org/10.1186/s12912-015-0098-2

Tam, M. (2000). Constructivism, instructional design, and technology: Implications for transforming distance learning. Educational Technology \& Society, 3(2), 50-60.

Topping, K. J. (2005). Trends in peer learning. Educational Psychology, 25(6), 631-645. https://doi.org/10.1080/01443410500345172

Zhu, E. (2007). Teaching with clickers. Center for Research on Learning and Teaching Occasional Papers, 22, $1-8$.

\section{Copyrights}

Copyright for this article is retained by the author, with first publication rights granted to the journal.

This is an open-access article distributed under the terms and conditions of the Creative Commons Attribution license (http://creativecommons.org/licenses/by/4.0/). 